\title{
Coal structure and reactivity changes induced by chemical demineralisation
}

F. Rubiera ${ }^{1 *}$, A. Arenillas ${ }^{1}$, C. Pevida ${ }^{1}$, R. García ${ }^{1}$, J.J. Pis ${ }^{1}$, K.M. Steel ${ }^{2}$ and J.W. Patrick ${ }^{2}$

${ }^{1}$ Department of Energy \& Environment. Instituto Nacional del Carbón, CSIC. Apartado 73. 33080-Oviedo. Spain

${ }^{2}$ Fuel Technology Group. School of Chemical, Environmental and Mining Engineering. Nottingham University. University Park. Nottingham, NG7 2RD. UK

\begin{abstract}
The aim of this work was to determine the influence that an advanced demineralisation procedure has on the combustion characteristics of coal. A high-volatile bituminous coal with $6.2 \%$ ash content was treated in a mixture of hydrofluoric and fluorosilicic acids $\left(\mathrm{HF} / \mathrm{H}_{2} \mathrm{SiF}_{6}\right)$. Nitric acid was used either as a pre-treatment, or as a washing stage after $\mathrm{HF} / \mathrm{H}_{2} \mathrm{SiF}_{6}$ demineralisation, with an ash content as low as $0.3 \%$ being attained in the latter case. The structural changes produced by the chemical treatment were evaluated by comparison of the FTIR spectra of the raw and treated coal samples. The devolatilisation and combustibility behaviour of the samples was studied by using a thermobalance coupled to a mass spectrometer (TGA-MS) for evolved gas analysis. The combustibility characteristics of the cleaned samples were clearly improved, there being a decrease in $\mathrm{SO}_{2}$ emissions.
\end{abstract}

Keywords: Coal demineralisation; Reactivity; TGA-MS

\section{Introduction}

The use of coal as an energy source and as a source of organic chemical feedstock may become more important in the future [1]. This tendency may be delayed, however, if the need for improved environmental performance is not met. Furthermore, in many instances, the mineral matter in coal prevents or inhibits its potential of utilisation. In order to make an acceptable substitute for carbon materials such as petroleum coke to make carbon electrodes 
for the aluminium smelting process, the mineral matter must be substantially reduced [2]. Currently, significant efforts are being made to develop processes for producing ultraclean coal $(<1 \mathrm{wt} \%$ mineral matter) that can be used in direct coal-fired gas turbines, marine diesel engines, boilers and furnaces as well as in advanced coal combustion technologies such as pressurised fluidised-bed combustors and integrated gasification combined cycle systems [3, 4]. The results presented in this paper are part of a project [5] aimed at examining the combustion characteristics and potential utilisation of extremely low ash, low sulphur coal produced by acid demineralisation, in advanced power generation processes. The main objective being to evaluate the influence that an intensive coal cleaning process has on the combustion behaviour and air isothermal gasification of coal. To this end acid cleaned coal samples were obtained and their combustibility characteristics were evaluated and compared with those of the parent coal. This was achieved by means of tests in a thermogravimetric analyser coupled to a mass spectrometer for evolved gas analysis.

\section{Experimental}

A high-volatile bituminous coal (HW) from Harworth colliery, UK, with 6.2\% ash content was used in this study. Demineralisation tests were carried out on the 1-2 mm size fraction of coal HW, based on the process patented by Lloyd and Turner [6], which utilises a 1:1 mixture of $\mathrm{HF} / \mathrm{H}_{2} \mathrm{SiF}_{6}$. This process was modified by using $\mathrm{HNO}_{3}$ as leaching agent. Treating the coal with $25 \mathrm{wt} \% \mathrm{HNO}_{3}$ for 16 hours at $60{ }^{\circ} \mathrm{C}$ followed by a $1: 1$ mixture of $25 \mathrm{wt} \% \mathrm{HF}$ and $25 \mathrm{wt} \%$ $\mathrm{H}_{2} \mathrm{SiF}_{6}$ for 8 hours at $60^{\circ} \mathrm{C}$, had the effect of reducing the ash content to $0.6 \%$. Reversing the leaching sequence and treating the coal with the mixed $\mathrm{HF} / \mathrm{H}_{2} \mathrm{SiF}_{6}$ first, and then by $\mathrm{HNO}_{3}$, was found to further reduce the ash content to $0.3 \%$. The ensuing combustibility tests were conducted on the latter demineralised coal sample (HW-D). The main characteristics of the parent coal and treated sample, ground to less than $150 \mu \mathrm{m}$, are given in Table 1. Representative samples were taken from the minus $150 \mu \mathrm{m}$ material and were dry sieved to 
generate a 38-150 $\mu \mathrm{m}$ particle size fraction for additional combustion tests in an entrained flow reactor [5]. The analyses of these 38-150 $\mu \mathrm{m}$ size fractions are also included in Table 1. Isothermal gasification and temperature-programmed combustion tests (TPC) were conducted in a thermogravimetric analyser (TGA). In the TPC tests a sample mass of approximately 10 mg was placed in a crucible, and the temperature was increased to $1000{ }^{\circ} \mathrm{C}$ at $15^{\circ} \mathrm{C} \min ^{-1}$ in $20 \%$ oxygen in argon $\left(50 \mathrm{~mL} \mathrm{~min}^{-1}\right)$. The reactivities of the chars were evaluated in the same atmosphere at $500{ }^{\circ} \mathrm{C}$. Previously, the temperature was raised to $850{ }^{\circ} \mathrm{C}$ in argon flow to devolatilise the samples. A quadrupole mass spectrometer coupled to the thermogravimetric analyser (TGA-MS) was used to record the gas evolution profiles during the combustion and devolatilisation tests. A detailed description of the methodology used can be found elsewhere [7].

\section{Results and discussion}

\section{Chemical Analyses}

From the results given in Table 1 it can be deduced that an ash reduction level of $95.2 \%$ together with a reduction of nearly $52 \%$ in total sulphur was attained after demineralisation. The demineralisation treatment did appear to have substantially modified the chemical composition of the HW-D sample: there is a clear increase in the volatile matter of the treated sample, and a strong increase in oxygen and nitrogen contents as shown in the ultimate analysis of Table 1.

\section{Combustibility assessment in TGA-MS}

The combustion DTG profiles (variation of the rate of mass loss with temperature) of the coals are displayed in Figure 1 . There is a peak at about $270{ }^{\circ} \mathrm{C}$ in the TPC profile of coal HW-D that is not present in the untreated coal. The compounds evolved during this stage are a more labile species (weaker bonds) than the normal coal volatile matter, because in the 
combustion profiles of the treated sample (Figure 1) the shoulder that corresponds to the loss of volatiles and char gasification takes place at higher temperatures. The values of the temperatures of $50 \%$ burnoff of organic material, $\mathrm{T}_{50}\left(530^{\circ} \mathrm{C}\right.$ and $513{ }^{\circ} \mathrm{C}$, for $\mathrm{HW}$ and $\mathrm{HW}$ $\mathrm{D}$, respectively) together with those of the burnout temperatures, $\mathrm{Tb}\left(670^{\circ} \mathrm{C}\right.$ and $645^{\circ} \mathrm{C}$, for HW and HW-D, respectively) clearly indicate that the demineralised coal is more reactive and can be burned more easily than the parent coal. The demineralisation treatment not only reduced the mineral matter content to a great extent but also improved the combustibility of the treated samples.

The higher reactivity of the cleaned coal, HW-D, was also confirmed by isothermal reactivity tests in $20 \%$ oxygen in argon at $500{ }^{\circ} \mathrm{C}$. The results displayed in Figure 2 indicate the higher reactivity of the char from coal HW-D, in comparison with that of the parent coal, HW. In the case of low rank coals it has been found that reactivity is primarily governed by the catalytic effect of organically bound alkali metals $[8,9]$. Thus, the demineralisation of low rank coals has a negative effect on their reactivity. However, for higher rank coals such as the bituminous coal studied in this work, an increase in reactivity was observed after demineralisation. This effect can be ascribed to a physical effect such as surface area or to a decrease in molecular order (active sites concentration) [10] due to loss of fluidity. The latter effect can be seen in Table 1, where the demineralised sample does not present signs of plasticity according to its free swelling index (FSI) value, while the parent coal has an FSI of 6.5 .

With regard to the gas evolution profiles during the TPC tests, no significant $\mathrm{SO}_{2}$ was detected for the demineralised sample in comparison with that from the parent coal. The most interesting feature of the gas analysis was the evolution presented by the $\mathrm{m} / \mathrm{z} 30\left(\mathrm{NO}^{+}\right)$signal. This is shown in Figure 3 for the samples under study. The $\mathrm{NO}^{+}$profile of the parent coal displays the behaviour normally found in bituminous coals [11]. However, when the $\mathrm{NO}^{+}$ profile of the demineralised coal is considered, a distinct behaviour can be observed. The two 
peaks in the char gasification zone have shifted to lower temperatures in comparison with those of the parent coal. In addition, a big peak at around $250{ }^{\circ} \mathrm{C}$ can be observed in Figure 3 for the demineralised sample. This peak is consistent with the mass loss observed at nearly the same temperature in the TPC profiles of the demineralised coal (cf. Figure 1). In addition, this low temperature peak is not a result of the combustion process because it also appeared at the same temperature during thermal treatment in an inert atmosphere of Argon, as can be seen in Figure 1, where the devolatilisation profile of the demineralised coal sample is also shown. The $\mathrm{m} / \mathrm{z} 30$ peak, which appeared in the low temperature region of the combustion profiles of the demineralised coal, is probably due to the decomposition of chemically stable nitro groups in agreement with the results of other authors who studied nitric acid oxidised samples by XPS and FTIR [12].

The modification of the organic structure of coal HW after acid treatment can be seen in the comparison of the FTIR spectra of the samples shown in Figure 4. Also included in this figure is a sample, HW-HF, obtained from demineralisation of the parent coal in hydrofluoric acid. This sample has an ash content of $2.2 \mathrm{wt} \%$. The FTIR spectrum of the untreated coal displays the typical bands of the organic part of a bituminous coal. It also shows significant bands arising from the inorganic matter. The bands at 3696 and $3619 \mathrm{~cm}^{-1}$ (both shoulders of the broad $\mathrm{O}-\mathrm{H}$ absorption) and, especially, those at 1032, 537 and $474 \mathrm{~cm}^{-1}$ are clearly assignable to kaolinite. These bands completely disappear in the spectra of coals HW-D and HW-HF.

The spectrum of the HW-D coal is characterised by the presence of some unusual strong narrow bands. Those centred at about 1530 and $1330 \mathrm{~cm}^{-1}$ can be assigned to the asymmetric and symmetric stretching vibrations, respectively, of aromatic nitro groups (Ar- $\left.\mathrm{NO}_{2}\right)[13,14]$. The stretching symmetric vibration of nitro groups bonded with alkane chains is observed at $1380 \mathrm{~cm}^{-1}$. The band at $2320 \mathrm{~cm}^{-1}$ may arise from nitrile groups $(\mathrm{C} \equiv \mathrm{N})$ stretching vibrations, although cumulative bonds such as those of diazo $\left(>\mathrm{C}=\mathrm{N}=\mathrm{N}^{+}\right)$and isocyanate $(-\mathrm{N}=\mathrm{C}=\mathrm{O})$ groups cannot be discarded. 
The FTIR spectra along with the evolved gas analysis by mass spectrometry provide evidence of the modifications produced in the structure of coal HW, with the incorporation of nitrogen functionalities in the demineralised $\mathrm{HW}$-D coal, and more specifically of nitro groups $\left(-\mathrm{NO}_{2}\right)$ in the aromatic carbon structures. However, ongoing research [5] has shown that thorough treatment with either distilled water or heat treatment can completely remove the absorbed nitrogen.

\section{Conclusions}

The demineralisation process modified the chemical composition of the treated sample, with an increase in the volatile matter, oxygen and nitrogen contents. This indicates a modification of the organic structure of the treated samples, with the incorporation of nitro groups, as confirmed by mass spectrometry and FTIR. Temperature programmed combustion and isothermal reactivity tests in a TGA showed that the demineralised sample presented much better combustibility characteristics than those of the parent coal, together with a concomitant decrease in the emissions of sulphur dioxide.

\section{Acknowledgements}

Work carried out with a financial grant from the European Coal and Steel Community (Project 7220-EA-017).

\section{References}

1. H.H. Schobert and C. Song, Fuel, 81 (2002) 15.

2. K.M. Steel, J. Besida, T.A. O’Donnell and D.G. Wood, Fuel Processing Technology, 70 (2001) 171.

3. K.M. Steel and J.W. Patrick, Fuel, 80 (2001) 2019. 
4. CSIRO Research Project 'Direct Firing of Coal into Turbines - Ultraclean Coal', November 2001.

5. The European Coal and Steel Community, Research Project $n^{\circ}$ 7220-EA-017 'Ultra-clean Coal for Power Generation’, Final Report, May 2001.

6. R. Lloyd and M.J. Turner, (1986) 'Method for the continous chemical reduction and removal of mineral matter contained in carbon structures’, Worldwide patent WO 86/04917.

7. A. Arenillas, F. Rubiera, J.J. Pis, J.M. Jones and A. Williams, Fuel, 78 (1999) 1779.

8. K. Miura, K. Hashimoto and P.L. Silveston, Fuel, 68 (1989) 1461.

9. L.R. Radovic, P.L. Walker and R.G. Jenkins, Fuel, 62 (1983) 209.

10. M.A. Serio, P.R. Solomon, R. Bassilakis and E.M. Suuberg, Prep. ACS, Div. Fuel Chem., 34 (1989) 9.

11. W.Wang, S.D. Brown, K.M. Thomas and J.C. Crelling, Fuel, 73 (1994) 341.

12. D.R. Mehandjiev, R.N. Nickolov and R.B. Ioncheva, Fuel, 76 (1997) 381.

13. J. Zawadzki, Carbon, 18 (1980) 281.

14. N.V. Bodoev, R. Gruber, V.A. Kucherenko, J. Guet, T. Khabarova, N. Cohaut, O. Heintz and N.N. Rokosova, Fuel, 77 (1998) 473. 
Table 1. Proximate and ultimate analyses, calorific value and free-swelling index of the parent and cleaned coal samples ( $<150 \mu \mathrm{m}$ and 38-150 $\mu \mathrm{m}$ ).

\begin{tabular}{|c|c|c|c|c|c|c|c|c|c|c|}
\hline \multirow[t]{2}{*}{ Sample } & \multicolumn{3}{|c|}{ Proximate Analysis (wt\%) } & \multicolumn{5}{|c|}{ Ultimate Analysis (wt\% db) } & \multirow[b]{2}{*}{$\begin{array}{c}\text { C.V. } \\
\text { (kcal/kg) }\end{array}$} & \multirow[b]{2}{*}{ FSI } \\
\hline & Moist. & $\begin{array}{l}\text { Ash } \\
\text { (db) }\end{array}$ & $\begin{array}{l}\text { V.M. } \\
\text { (db) }\end{array}$ & $\mathrm{C}$ & $\mathrm{H}$ & $\mathrm{N}$ & $\mathrm{S}$ & $\mathrm{O}^{\mathrm{a}}$ & & \\
\hline HW $(<150 \mu m)$ & 2.2 & 6.2 & 34.7 & 77.2 & 5.5 & 1.9 & 2.7 & 6.5 & 7761 & 6.5 \\
\hline 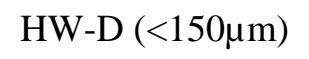 & 3.0 & 0.3 & 41.5 & 70.7 & 4.1 & 5.3 & 1.3 & 18.3 & 6705 & 0 \\
\hline HW $(38-150 \mu m)$ & 1.8 & 5.7 & 35.6 & 76.8 & 6.0 & 1.8 & 2.7 & 7.0 & n.d. & n.d. \\
\hline 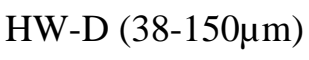 & 2.6 & 0.2 & 38.7 & 70.7 & 5.6 & 4.8 & 1.3 & 17.4 & n.d. & n.d. \\
\hline
\end{tabular}

${ }^{\mathrm{a}}$ By difference 


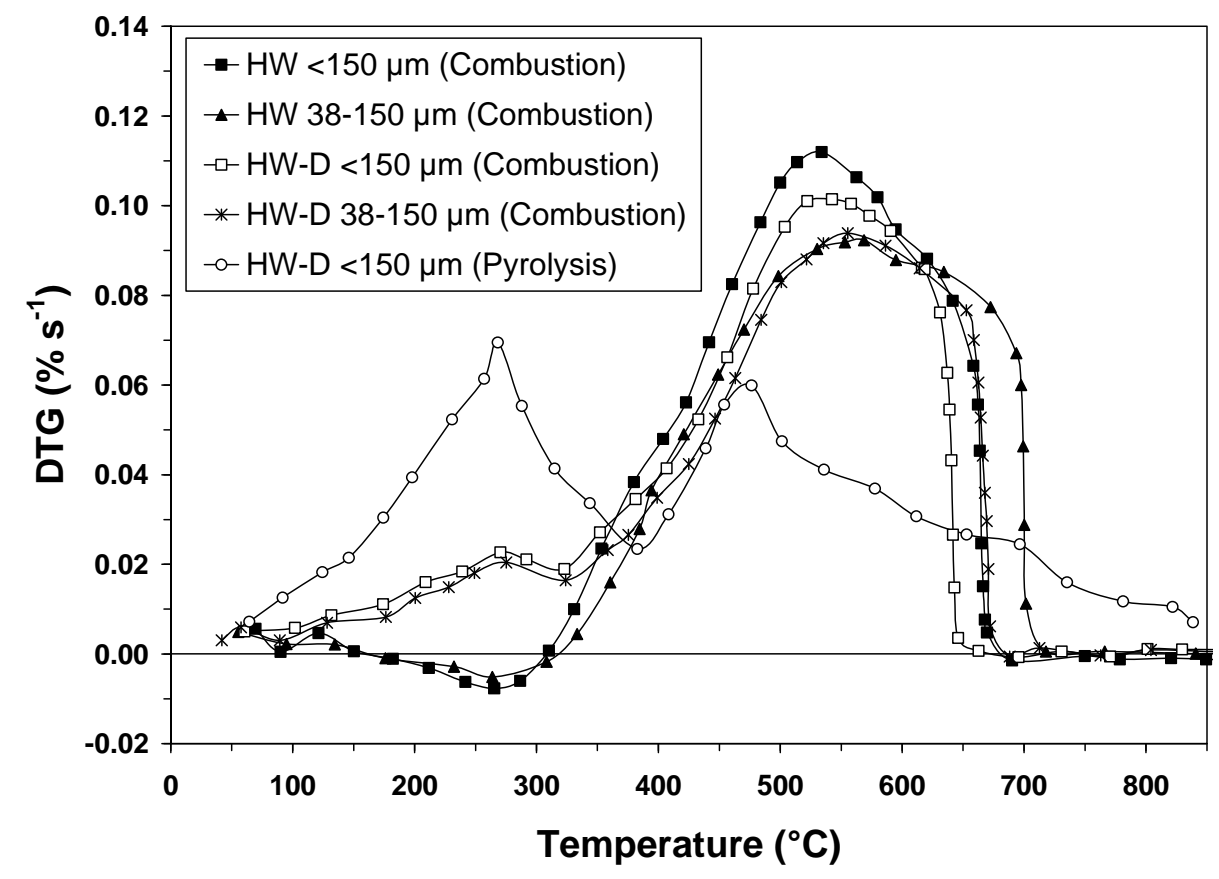

Figure 1. Temperature programmed combustion profiles of coals HW and HW-D, and pyrolysis profile of the demineralised coal, HW-D. 


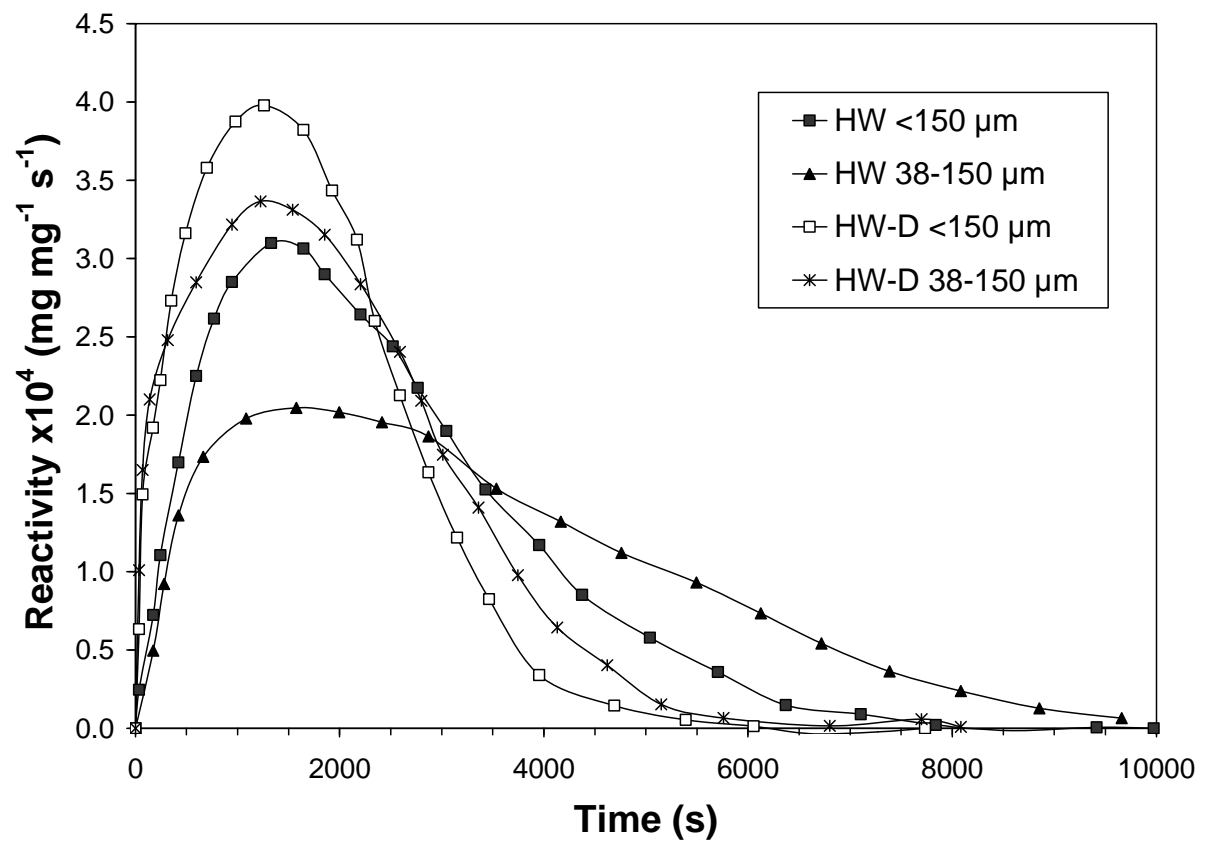

Figure 2. Variation with time of the reactivity, determined at $500{ }^{\circ} \mathrm{C}$, of the chars from the parent coal, HW, and the demineralised coal, HW-D. 


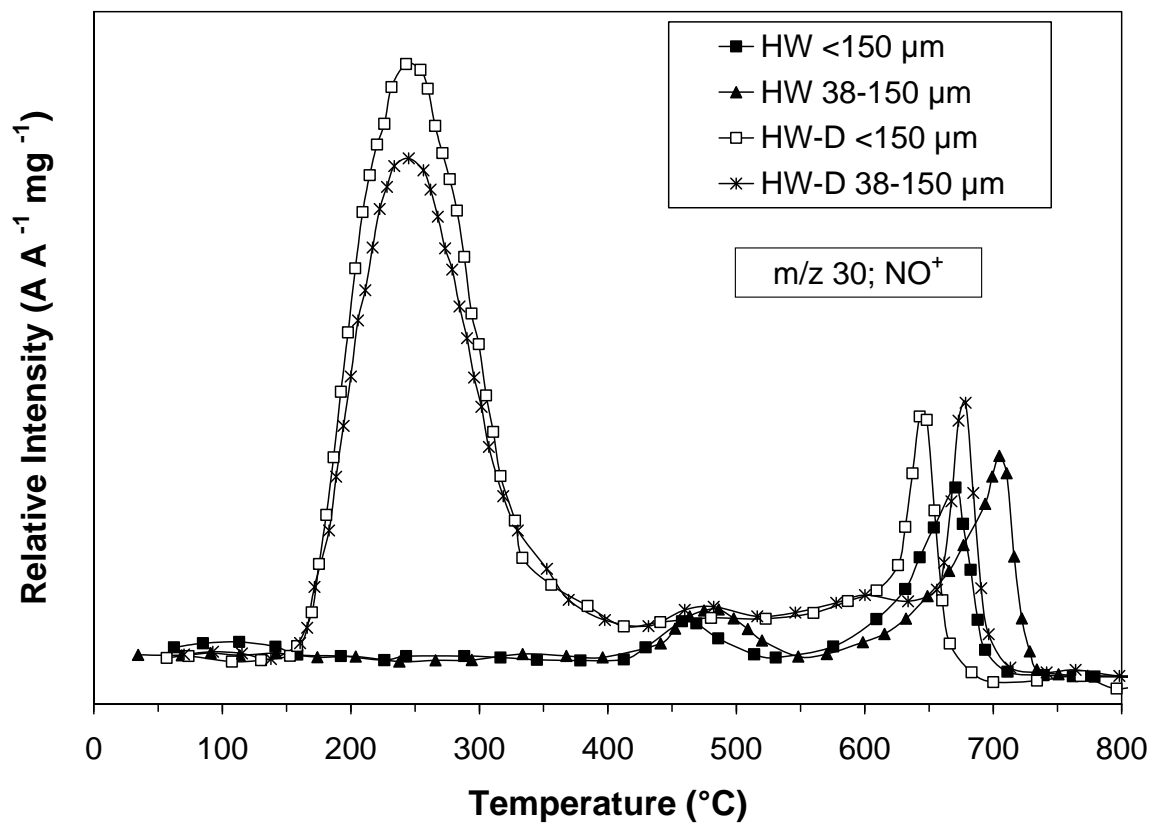

Figure $3 \mathrm{NO}^{+}$evolution profiles, followed by mass spectrometry, during combustion of coals HW and HW-D. 


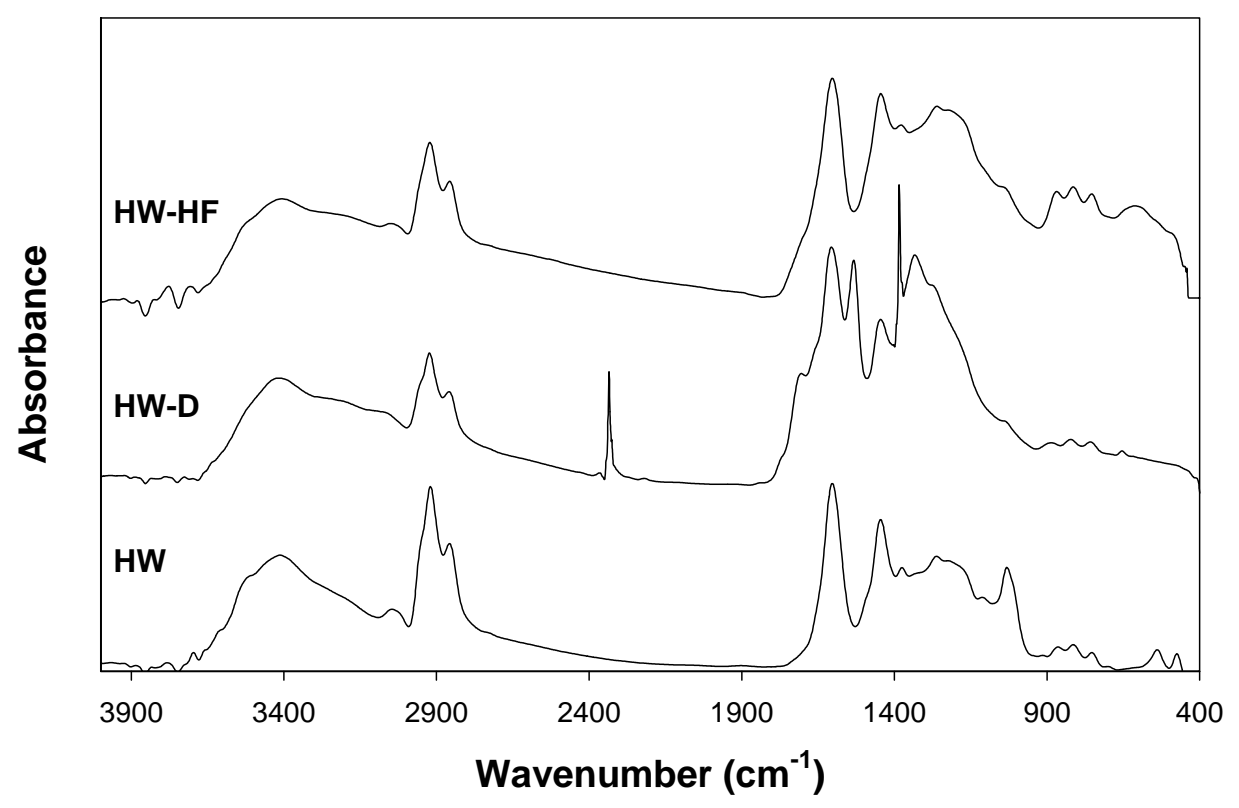

Figure 4. FTIR spectra of the parent coal, HW, and of the demineralised coals, HW-D and HW-HF. 